\title{
Perencanaan Ulang Sistem Pengkondisian Udara pada Lantai 1 dan 2 Gedung Surabaya Suite Hotel di Surabaya
}

\author{
Wahyu Priatna dan Ary Bachtiar Krishna Putra \\ Jurusan Teknik Mesin, Fakultas Teknologi Industri, Institut Teknologi Sepuluh Nopember (ITS) \\ Jl. Arief Rahman Hakim, Surabaya 60111 Indonesia \\ e-mail: arybach@me.its.ac.id
}

\begin{abstract}
Abstrak-Sistem pengkondisian udara menggunakan Air conditioner tidak hanya berfungsi sebagai pendingin, melainkan dituntut untuk dapat menghasilkan suatu kondisi udara nyaman. Perencanaan ulang yang dilakukan bertujuan untuk mengetahui kondisi peralatan yang digunakan apakah telah sesuai dengan kebutuhan atau tidak. Perencanaan ulang ini dilakukan dengan perhitungan beban pendinginan dari setiap ruangan dan penurunan tekanan pada saluran ducting dengan menggunakan metode CLTD (Cooling Load Temperature Difference) dengan memperhatikan letak geografis, dimensi, konstruksi dan kondisi luar bangunan. Desain temperatur ruangan didasarkan pada ASHRAE (American Society of Heating, Refrigerating and AirConditioning Engineers) standard comfort zone sedangkan desain di luar gedung didasarkan pada data dari BMKG Juanda. Dari hasil perhitungan beban pendinginan dan kapasitas udara, didapatkan peralatan pengkondisian udara yakni AHU dan FCU yang mengalami kelebihan kapasitas pendinginan dan kapasitas udara suplai menyebabkan ruangan yang dikondisikan nantinya tidak berada pada kondisi nyaman dikarenakan temperatur yang dihasilkan lebih rendah dari temperatur ruangan pada kondisi nyaman. Dari hasil perhitungan, juga didapatkan peralatan pengkondisian udara dengan kapasitas yang lebih rendah dari kapasitas perencanaan ulang pada kondisi nyaman menyebabkan kondisi ruangan tidak lagi pada kondisi nyaman. Dari hasil perhitungan perencanaan ulang juga didapatkan besar fan static pressure yang dibutuhkan oleh tiap peralatan pengkondisian udara untuk mensirkulasikan udara didalam system termasuk menyalurkan udara suplai keruangan yang dikondisikan dimana kebutuhan fan static pressure terbesar ialah pada FCU 1-6 sebesar 318,33 Pa dan terkecil pada FCU 206 sebesar 1,08 Pa.
\end{abstract}

Kata Kunci-beban pendinginan, fan static pressure, pengkondisian udara

\section{PENDAHULUAN}

$\mathrm{S}$ ISTEM pengkondisian udara dewasa ini memegang peranan penting. Hal tersebut terlihat dengan semakin banyak digunakannya perlengkapan ini secara luas di berbagai bidang kegiatan manusia dikarenakan manusia dapat melakukan aktivitasnya secara maksimal jika Ia merasa nyaman dengan lingkungan disekitarnya. Suatu sistem pengkondisian udara dalam penggunaannya memerlukan energi yang besar dalam bentuk energi listrik. Disisi lain ketersediaan akan energi semakin menipis, ditambah lagi dengan jumlah populasi manusia yang semakin hari semakin meningkat menyebabkan konsumsi energi semakin besar. Tanpa adanya peralatan ini banyak kegiatan yang tidak dapat dilakukan dengan baik, utamanya kegiatan yang dilakukan dalam ruangan, misalnya didalam gedung bertingkat, pabrik, rumah sakit, dan gedung perkantoran. Salah satu gedung bertingkat yang memerlukan sistem pengkondisian udara adalah hotel.

Pada dasarnya prinsip kerja dari Air Conditioner (AC) hampir sama dengan refrigerasi, namun Air Conditioner (AC) sendiri tidak hanya berfungsi sebagai pendingin, tetapi juga dituntut untuk dapat menghasilkan suatu kondisi udara yang nyaman. Untuk mendapatkan keadaan tersebut dilakukan dengan jalan pengontrolan terhadap kondisi udara yang meliputi suhu, kelembaban, gerakan udara, tekanan udara, pada sistem tata udara 'Gedung Surabaya Suite Hotel di Surabaya'.

Sistem pengkondisian udara pada bangunan yang besar sangat membutuhkan efisiensi dalam penggunaan energi. Dengan sistem pengkondisian udara yang benar dan sesuai dengan spesifikasinya serta perhitungan cooling load yang benar akan berkaitan dengan kenyamanan pekerja dan pengunjung. Dengan melakukan analisa energi pada ' 'Air Handling Unit (AHU) dan Fan Coil Unit (FCU)" yang digunakan dalam sistem tata udara pada gedung Surabaya Suite Hotel di Surabaya, memungkinkan kita untuk dapat mengetahui apakah kondisi ruangan yang dikondisikan telah mencapai tingkat kenyamanan yang baik serta untuk mengetahui sumber pemborosan energi yang mungkin terjadi. Oleh karena itu, penulis tertarik untuk mengambil bahasan tentang pengkondisian udara ini sebagai bahan Tugas Akhir dengan objek perancangan pada area Gedung Surabaya Suite Hotel di Surabaya.

\section{II.METODE PENELITIAN}

Penelitian dilakukan pada setiap peralatan pengkondisian udara beserta ruangan yang disuplai dengan mengumpulkan data primer dan sekunder. Data primer diperoleh dengan cara pengukuran langsung sesuai dengan kondisi di lapangan. Pengumpulan data sekunder seperti kapasitas pendinginan dan kapasitas udara desain awal, denah bangunan, denah saluran udara, bahan dinding, dan luasan tiap ruangan diperoleh dari pihak pengelola gedung hotel.

Perencanaan ulang sistem pengkondisian udara dengan metode CLTD (cooling load temperature difference) didasarkan pada ASHRAE-Handbook-1997 Fundamental [1]. Perhitungan besar kebutuhan fan static pressure untuk tiap peralatan pengkondisian udara didasarkan pada perhitungan pumps, fans, and blowers in fluid systems [2]. 


\section{A. Beban Penghuni}

Beban penghuni dan pengunjung adalah beban pendinginan yang diakibatkan oleh adanya heat gain yang dihasilkan oleh tubuh manusia. Besarnya heat gain yang dihasilkan oleh tubuh manusia dapat diperoleh dengan persamaan:

$Q_{S}=\frac{q_{s}}{\text { person }} \times$ no. of people $\times C L F$

$Q_{1}=\frac{q_{1}}{\text { person }} \times$ no. of people $\times C L F$

$Q_{\text {total }}=Q_{s}+Q_{1}$

\section{B. Beban Penerangan}

Beban penerangan lampu adalah beban yang disebabkan oleh adanya heat gain yang dihasilkan oleh lampu yang menyala. Untuk memperoleh beban penerangan digunakan persamaan:

$Q=3,41 \times q_{i} \times F_{u} \times F_{s} \times C L F$

\section{Beban Peralatan}

Semua peralatan listrik yang digunakan dalam gedung akan menghasilkan panas. Untuk memperoleh besarnya heat gain yang dihasilkan oleh peralatan, digunakan persamaan:

$Q_{\text {peralatan }}=3,41 \times 0,16 \times P \times C L F$

\section{Beban Partisi}

Beban partisi merupakan penambahan panas yang disebabkan oleh adanya perbedaan temperatur antara ruangan yang dikondisikan terhadap ruangan yang tidak dikondisikan. Besarnya penambahan kalor dapat diperoleh dari persamaan:

$Q=U \times A \times T D$

\section{E. Beban Radiasi Melalui Kaca}

Beban radiasi melalui kaca merupakan beban pendinginan eksternal. Besarnya beban radiasi melalui kaca dapat dihitung dengan persamaan:

$Q=S H G F \times A \times S C \times C L F$

\section{F. Beban Transmisi Melalui Dinding Luar dan Kaca}

Beban transmisi dinding luar dan kaca merupakan beban yang diakibatkan oleh adanya perpindahan panas secara konduksi dari luar ruangan kedalam ruangan yang dikondisikan melalui dinding luar dan kaca. Untuk memperoleh nilai beban transmisi dinding luar dan kaca, digunakan persamaan:

$Q=U \times A \times C L T D C$

dimana:

$$
\begin{aligned}
C L T D c_{\text {dinding }}= & (C L T D+L M) \times K+\left(78-T_{R}\right)+\left(T_{o}\right. \\
& -85) \\
C L T D c_{\text {kaca }}= & C L T D+\left(78-T_{R}\right)+\left(T_{o}-85\right)
\end{aligned}
$$

\section{G. Beban Infiltrasi dan Ventilasi}

Beban infiltrasi ialah laju aliran udara yang tidak terkendali dan tidak disengaja masuk ke dalam ruangan melalui celah dan bukaan lainnya akibat penggunaan pintu oleh penghuni. Beban ventilasi sendiri ialah udara yang dibawa masuk kedalam ruangan dengan sengaja secara mekanis. Besarnya beban infiltrasi dan ventilasi dapat dihitung menggunakan persamaan:

$Q_{s}=1,1 \times \Delta T \times s c f m$

$Q_{l}=4840 \times \Delta w \times s c f m$

$Q_{\text {total }}=Q_{s}+Q_{l}$

\section{H. Beban Pendinginan Saluran Udara}

Ketika saluran udara melewati ruangan yang tidak dikondisikan, maka akan terjadi perpindahan panas antara permukaan ducting terhadap udara luar. Berdasarkan buku panduan Fundamental of Heat and Mass Transfer, by Frank P. Incropera [3], Besarnya perpindahan panas yang terjadi dapat dihitung dengan persamaan:

$Q=U \times A \times T D$

\section{Room Sensible Heat Factor (RSHF)}

$R S H F$ adalah perbandingan beban kalor sensibel ruangan terhadap keseluruhan beban kalor ruangan. Persamaan yang digunakan untuk menghitung nilai $R S H F$ adalah:

$R S H F=\frac{R S H G}{R T H G}$

\section{J. Grand Sensible Heat Factor (GSHF)}

$G S H F$ adalah perbandingan total kalor sensibel dengan total kalor seluruhnya yang harus ditanggung oleh peralatan pengkondisian udara. Persamaan yang digunakan untuk menghitung nilai $G S H F$ adalah:

$G S H F=\frac{T S H}{G T H}$

\section{K. Debit Udara Zona Hotel}

Debit udara zona hotel adalah jumlah kebutuhan udara suplai kedalam ruangan sehingga menjadikan ruangan suplai berada pada kondisi nyaman. Persamaan yang digunakan untuk menghitung debit udara adalah:

Debit Udara $=\frac{R S H G}{1.1\left(T_{r}-T_{S}\right)}$

\section{Kebutuhan Fan Static Pressure}

Fan static pressure adalah tekanan statis yang dibutuhkan oleh fan untuk melawan friction disepanjang saluran udara. Berdasarkan buku panduan Fluid Mechanics, by R.W. Fox [2], persamaan yang dapat digunakan untuk menghitung kebutuhan fan static pressure adalah:

$\left(\frac{P_{1}}{\rho}+\alpha_{1} \frac{V_{1}{ }^{2}}{2}+g z_{1}\right)-\left(\frac{P_{2}}{\rho}+\alpha_{2} \frac{V_{2}^{2}}{2}+g z_{2}\right)=h_{l t}-\Delta h_{f a n}$

\section{ANALISIS DAN PEMBAHASAN}

\section{A. Analisa Beban Pendinginan}

Analisa beban pendinginan adalah dengan membandingkan kapasitas pendinginan desain awal (kapasitas pendinginan peralatan yang terinstal) dengan kebutuhan beban pendinginan hasil perhitungan dengan standar ASHRAE. Kondisi nyaman dapat tercapai jika kapasitas pendinginan besarnya sama dengan beban pendinginan. 
Berdasarkan tabel perbandingan kapasitas pendinginan terhadap beban pendinginan pada lantai 1, terdapat peralatan yang mengalami over design dimana kapasitas pendinginannya jauh lebih besar dari beban pendinginan. Pada tabel yang sama juga terdapat peralatan dengan kapasitas pendinginan jauh lebih kecil dari beban pendinginan. Sedangkan peralatan pengkondisian udara dengan kapasitas pendinginan yang sama besar dengan beban pendinginantidak ditemukan. Hal tersebut mengindikasikan bahwa keseluruhan peralatan pengkondisian udara pada lantai 1 tidak dapat menghasilkan ruangan suplai dengan kondisi yang nyaman.

Tabel 1.

Perbandingan Kapasitas Pendinginan Terhadap Beban Pendinginan Peralatan Pengkondisian Udara Pada Lantai 1

\begin{tabular}{ccc}
\hline AHU \& FCU & \multicolumn{2}{c}{ Cooling Load (Btu/hr) } \\
Lt.1 & Desain Awal & Perencanaan Ulang \\
\hline AHU 1-1 & 180000 & 198316.94 \\
AHU 1-2 & 180000 & 198313.75 \\
FCU 1-1 & 36000 & 50886.69 \\
FCU 1-2 & 36000 & 53937.44 \\
FCU 1-3 & 43800 & 60051.42 \\
FCU 1-4 & 13200 & 4998.51 \\
FCU 1-6 & 108000 & 158627.85 \\
FCU 1-7 & 36000 & 63478.94 \\
FCU 1-8 & 36000 & 63503.47 \\
FCU 1-9 & 36000 & 26135.72 \\
FCU 1-10 & 24000 & 10902.84 \\
FCU 1-11 & 36000 & 69078.68 \\
\hline \hline
\end{tabular}

Tabel 2.

Perbandingan Kapasitas Pendinginan Terhadap Beban Pendinginan Peralatan Pengkondisian Udara Pada Lantai 2

\begin{tabular}{lcc}
\hline \hline & \multicolumn{2}{c}{ Cooling Load (Btu/hr) } \\
FCU Lt.2 & Desain Awal & Perencanaan Ulang \\
\hline & & \\
\hline FCU 201 & 6630 & 11117.25 \\
FCU 202 & 13800 & 7463.87 \\
FCU 203 & 6630 & 11117.25 \\
FCU 204 & 13800 & 9263.59 \\
FCU 205 & 26130 & 14755.85 \\
FCU 206 & 28410 & 9942.54 \\
FCU 207 & 16110 & 7828.84 \\
FCU 208 & 17310 & 10573.91 \\
FCU 209 & 6630 & 11118.92 \\
FCU 210 & 13800 & 7463.87 \\
FCU 211 & 6630 & 11118.92 \\
FCU 212 & 13800 & 7463.87 \\
FCU 214 & 13800 & 7463.87 \\
FCU 215 & 6630 & 11118.92 \\
FCU 216 & 17310 & 10965.75 \\
FCU 217 & 13680 & 7413.95 \\
FCU 218 & 13680 & 7413.95 \\
FCU 219 & 13680 & 10453.97 \\
FCU 220 & 22050 & 14903.43 \\
FCU 221 & 6630 & 7817.46 \\
FCU 222 & 13800 & 9807.50 \\
FCU 223 & 6630 & 7817.46 \\
FCU 224 & 13800 & 11985.15 \\
FCU 225 & 15150 & 19324.51 \\
FCU 226 & 16710 & 12518.12 \\
FCU 227 & 13680 & 12519.38 \\
FCU 228 & 13680 & 12519.38 \\
FCU 229 & 13680 & 12519.38 \\
FCU 230 & 16710 & 10949.65 \\
FCU 231 & 6630 & 7819.13 \\
FCU 232 & 13800 & 9807.50 \\
FCU 233 & 6630 & 7819.13 \\
FCU 234 & 13800 & 9807.50 \\
FCU 235 & 6630 & 7819.13 \\
& & \\
& &
\end{tabular}

\begin{tabular}{lcc} 
FCU 236 & 13800 & 9807.50 \\
FCU 237 & 21540 & 21872.40 \\
FCU 238 & 13680 & 10453.97 \\
FCU 239 & 13680 & 7413.95 \\
FCU 240 & 13680 & 7413.95 \\
FCU 241 & 16710 & 10822.03 \\
\hline \hline
\end{tabular}

Berdasarkan tabel perbandingan kapasitas pendinginan terhadap beban pendinginan pada lantai 2 diatas, juga tidak ditemukan peralatan dengan kapasitas pendinginan yang sama besar dengan beban pendinginan. Hal tersebut juga mengindikasikan bahwa keseluruhan peralatan pengkondisian udara pada lantai 1 tidak dapat menghasilkan ruangan suplai dengan kondisi yang nyaman.

\section{B. Analisa Debit Udara Suplai}

Setelah nilai beban pendinginan didapatkan, maka dilakukan perhitungan nilai RSHF dan GSHF. Selanjutnya dilakukan pengeplotan pada bagan psikrometrik untuk mengetahui kondisi udara suplai. Data awal temperatur lingkungan dari BMKG Janda Surabaya sebesar $93.2^{\circ} \mathrm{F}$ dan RH sebesar $70 \%$, sedangkan temperature ruang desain sebesar $73.4^{\circ} \mathrm{F}$ dan $\mathrm{RH}$ sebesar 50\%. Berdasarkan buku panduan Fundamental of Engineering Thermodinamics, by M.J. Moran [4] dengan mengasumsikan kondisi yang terjadi adalah adiabatik mixing, dengan perencanaan ulang udara campuran mengandung $10 \%$ fresh air maka kondisi campuran didapatkan dengan persamaan:



Gambar 1. Skema Adiabatik Mixing

$$
\begin{array}{ll}
m_{1} \cdot h_{1}+m_{2} \cdot h_{2}=m_{3} \cdot h_{3} & \text { Energi } \\
m_{1}+m_{2}=m_{3} & \text { massa udara } \\
m_{1} \cdot W_{1}+m_{2} \cdot W_{2}=m_{3} \cdot W_{3} & \text { massa uap air }
\end{array}
$$

Sehingga didapatkan kondisi campuran pada $\mathrm{h}_{3}$ sebesar 29.65 Btu/lb d.a. dengan $\mathrm{W}_{3}$ sebesar $0.0105 \mathrm{lb} / \mathrm{lb}$ d.air. dengan nilai RSHF sebesar 0.88 dan GSHF sebesar 0.78, maka dari hasil pengeplotan pada bagan psikrometrik didapatkan kondisi udara suplai dengan temperatur sebesar $53.5^{\circ} \mathrm{F}$ dan $\mathrm{W}$ sebesar $0.00855 \mathrm{lb} / \mathrm{lb}$ d.a. seperti yang ditunjukkan oleh gambar dibawah ini: 


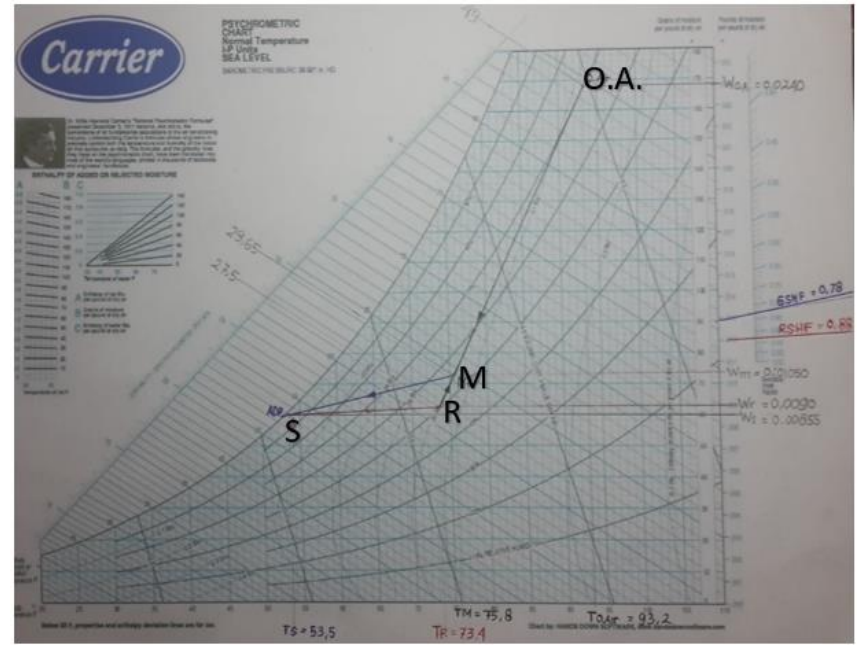

Gambar 2. Aplikasi Bagan Psikrometrik

Sistem pengkondisian udara pada AHU dan FCU dapat digambarkan pada bagan psikrometrik seperti yang ditunjukkan pada gambar diatas. Proses pencampuran return air (R) dengan fresh air (O.A.) diinterpretasikan oleh garis yang menghubungkan antara titik O.A. terhadap titik R. Proses pencampuran ini akan menghasilkan udara mixing air yang dilambangkan oleh titik $\mathrm{M}$. Udara yang telah bercampur (mixing air) kemudian didinginkan dan akan mengalami pengurangan kelembaban ketika melewati koil pendingin (cooling coil). Ketika mixing air melewati koil pendingin, tidak keseluruhan udara akan tepat melintasi permukaan koil dikarenakan adanya jarak antar koil menyebabkan sebagian udara tidak tepat melintasi permukaan koil (non $A D P$ ). Udara yang tepat melintasi permukaan koil dan udara yang tidak tepat melintasi permukaan koil akan bercampur kembali setelah melewati koil pendingin sehingga udara yang keluar dari koil pendingin memiliki temperatur dan rasio humidity yang lebih besar dari kondisi apparatus dew point $(A D P)$. Proses yang terjadi ketika mixing air melewati koil pendingin, diperlihatkan oleh gambar berikut:

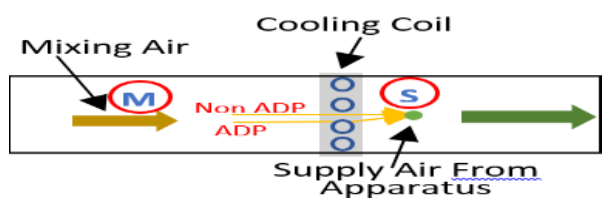

Gambar 3. Proses Mixing Air Ketika Melalui Koil Pendingin

Proses udara yang tepat melalui koil pendinginan di interpretasikan oleh garis yang menghubungkan antara titik $M$ terhadap titik ADP seperti yang ditunjukkan pada gambar 2 . Sedangkan proses pencampuranan antara udara yang tepat melintasi permukaan koil pendingin dengan udara yang tidak tepat melintasi permukaan koil pendingin diinterpretasikan oleh garis yang menghubungkan antara titik ADP terhadap titik S. Udara yang telah didinginkan dan telah mengalami pengurangan kelembaban tersebut (Supply air from apparatus), disalurkan ke ruangan melalui supply fan, supply duct, dan diffuser. Selanjutnya udara tersebut akan menyerap beban pendinginan baik dari ruangan maupun dari supply fan dan supply ducting sehingga membentuk udara ruangan (room air). Proses tersebut diinterpretasikan oleh garis yang menghubungkan antara titik $\mathbf{S}$ terhadap titik $\mathbf{R}$ pada gambar 2.
Setelah kondisi udara suplai diketahui, selanjutnya dilakukan perhitungan perencanaan kebutuhan debit udara suplai. Analisa debit udara suplai dilakukan dengan membandingkan debit udara desain awal dengan debit udara perencanaan ulang (hasil perhitungan pada kondisi nyaman).

Tabel 3.

Perbandingan Debit Udara Desain Awal terhadap Debit Udara Perencanaan Ulang Pada Lantai 1

\begin{tabular}{ccc}
\hline \hline \multirow{2}{*}{$\begin{array}{c}\text { AHU \& FCU } \\
\text { Lt.1 }\end{array}$} & \multicolumn{2}{c}{ Air flow (ft $\mathbf{3} / \mathbf{m i n})$} \\
\hline AHU 1-1 & 6000 & Perencanaan Ulang \\
AHU 1-2 & 6000 & 6094.55 \\
FCU 1-1 & 1200 & 6094.72 \\
FCU 1-2 & 1200 & 1701.12 \\
FCU 1-3 & 1460 & 1830.14 \\
FCU 1-4 & 440 & 1986.93 \\
FCU 1-6 & 3600 & 123.49 \\
FCU 1-7 & 1200 & 5987.45 \\
FCU 1-8 & 1200 & 2306.97 \\
FCU 1-9 & 1200 & 2306.72 \\
FCU 1-10 & 800 & 857.66 \\
FCU 1-11 & 1200 & 325.49 \\
\hline \hline
\end{tabular}

Berdasarkan tabel perbandingan debit udara desain awal terhadap debit udara perencanaan ulang pada lantai 1 diatas, sebagian besar peralatan mengalami kekurangan debit udara suplai dimana akan menghasilkan kondisi ruangan dengan temperatur lebih tinggi dari kondisi nyaman. Sedangkan sisanya mengalami kelebihan kapasitas udara suplai yang nantinya akan menyebabkan kondisi ruangan tidak lagi pada kondisi nyaman melainkan temperatur yang dihasilkan lebih rendah dari temperatur nyaman.

Tabel 4.

Perbandingan Debit Udara Desain Awal terhadap Debit Udara Perencanaan Ulang Pada Lantai 2

\begin{tabular}{lcc}
\multicolumn{3}{c}{ Air flow (ft $\left.^{3} / \mathbf{m i n}\right)$} \\
\hline \hline FCU Lt.2 & Desain Awal & Perencanaan Ulang \\
& & \\
\hline FCU 201 & 221 & 404.09 \\
FCU 202 & 460 & 261.18 \\
FCU 203 & 221 & 404.09 \\
FCU 204 & 460 & 313.30 \\
FCU 205 & 871 & 516.12 \\
FCU 206 & 947 & 343.12 \\
FCU 207 & 537 & 266.23 \\
FCU 208 & 577 & 366.56 \\
FCU 209 & 221 & 404.17 \\
FCU 210 & 460 & 261.18 \\
FCU 211 & 221 & 404.17 \\
FCU 212 & 460 & 261.18 \\
FCU 214 & 460 & 261.18 \\
FCU 215 & 221 & 404.17 \\
FCU 216 & 577 & 380.85 \\
FCU 217 & 456 & 258.11 \\
FCU 218 & 456 & 258.11 \\
FCU 219 & 456 & 362.14 \\
FCU 220 & 735 & 527.76 \\
FCU 221 & 221 & 265.57 \\
FCU 222 & 460 & 351.05 \\
FCU 223 & 221 & 265.57 \\
FCU 224 & 460 & 499.24 \\
FCU 225 & 505 & 711.19 \\
FCU 226 & 557 & 527.96 \\
FCU 227 & 456 & 528.04 \\
FCU 228 & 456 & 528.04 \\
FCU 229 & 456 & 528.04 \\
& &
\end{tabular}




\begin{tabular}{lll} 
FCU 230 & 577 & 437.48 \\
FCU 231 & 221 & 265.67 \\
FCU 232 & 460 & 351.05 \\
FCU 233 & 221 & 265.67 \\
FCU 234 & 460 & 351.05 \\
FCU 235 & 221 & 265.67 \\
FCU 236 & 460 & 351.05 \\
FCU 237 & 718 & 847.70 \\
FCU 238 & 456 & 380.18 \\
FCU 239 & 456 & 258.11 \\
FCU 240 & 456 & 258.11 \\
FCU 241 & 577 & 379.12 \\
\hline
\end{tabular}

Berdasarkan tabel perbandingan debit udara desain awal terhadap debit udara perencanaan ulang pada lantai 2 diatas, tidak ditemukan peralatan dengan kapasitas pendinginan yang sama besar dengan beban pendinginan melainkan keseluruhan peralatan pengkondisian udara mengalami kelebihan dan kekurangan debit udara suplai yang nantinya menyebabkan kondisi ruangan terasa panas untuk yang mengalami kekurangan debit udara suplai sedangkan yang mengalami kelebihan udara suplai justru menghasilkan ruangan dengan temperatur yang terlalu dingin. Hal tersebut mengindikasikan bahwa keseluruhan dari peralatan pengkondisian udara yang berada pada lantai 2 tidak dapat menghasilkan ruangan suplai dengan kondisi yang nyaman.

\section{Analisa Kebutuhan Fan Static Pressure}

Perhitungan kebutuhan fan static pressure ini didasarkan pada kesamaan pressure drop pada setiap percabangan (equal friction method). Berdasarkan buku panduan Air Conditioning And Systems An Energy Approach, by Edward G. Pita [5], untuk equal friction method, pressure drop hanya dihitung pada saluran terpanjang saja. Pada gedung Surabaya Suite Hotel, Unit pengkondsian udara yang terpasang (AHU dan FCU) mensirkulasikan sebagian besar udara yang ada didalam ruangan dimana terdapat juga udara yang dibuang keluar ruangan (exhaust) dan digantikan dengan udara segar (fresh air) dengan jumlah yang sama. Sistem pengkondisian udara yang terpasang dapat digambarkan sebagai berikut:



Gambar 4.Model Sistem Pengkondisian Udara

besarnya fan static pressure yang dibutuhkan oleh fan untuk mensirkulasikan udara kedalam ruangan melalui saluran udara, dapat direpresentasikan oleh head kecepatan yang diakibatkan karena adanya perbedaan antara kecepatan aliran fluida pada sisi hisap terhadap sisi tekan serta headloss atau pressure drop disepanjang saluran udara.

Tabel 5.

Total Kebutuhan Fan Static Pressure Peralatan Pengkondisian Udara Pada Lantai 1

\begin{tabular}{cccccccc}
\hline \hline $\begin{array}{c}\text { AHU \& } \\
\text { FCU } \\
\text { Lt.1 }\end{array}$ & $\begin{array}{c}\text { Inlet } \\
(\mathbf{P a})\end{array}$ & $\begin{array}{c}\text { Exit } \\
(\mathbf{P a})\end{array}$ & $\begin{array}{c}\text { Head } \\
\text { Kecepatan } \\
(\mathbf{P a})\end{array}$ & $\begin{array}{c}\text { Saluran } \\
\text { Lurus } \\
(\mathbf{P a})\end{array}$ & $\begin{array}{c}\text { Elbow } \\
\mathbf{9 0} \\
(\mathbf{P a})\end{array}$ & $\begin{array}{c}\text { Diverging } \\
\text { Wye } \\
(\mathbf{P a})\end{array}$ & $\begin{array}{c}\text { Static } \\
\text { Pressure } \\
(\mathbf{P a})\end{array}$ \\
\hline AHU 1-1 & 21.23 & 34.33 & 15.24 & 88.56 & 13.33 & 138.66 & 311.35 \\
AHU 1-2 & 21.23 & 34.33 & 15.24 & 87.75 & 12.75 & 138.76 & 310.05 \\
FCU 1-1 & 13.05 & 21.92 & 6.46 & 139.92 & 19.13 & 71.30 & 271.79 \\
FCU 1-2 & 14.63 & 24.46 & 7.71 & 121.03 & 22.86 & 62.97 & 253.66
\end{tabular}

\begin{tabular}{cccccccc} 
FCU 1-6 & 28.05 & 45.58 & 13.49 & 53.25 & 9.15 & 168.82 & 318.33 \\
FCU 1-7 & 18.75 & 44.24 & 8.45 & 71.62 & 21.02 & 130.89 & 294.98 \\
FCU 1-8 & 17.53 & 39.22 & 10.26 & 86.93 & 10.18 & 139.63 & 303.75 \\
FCU 1-9 & 19.29 & 36.97 & 3.47 & 105.41 & 9.65 & 51.99 & 226.78 \\
FCU 1-10 & 4.61 & 9.54 & 4.06 & 54.85 & 0.92 & 17.91 & 91.89 \\
FCU 1-11 & 15.18 & 25.02 & 4.13 & 106.57 & 15.24 & 75.18 & 241.33 \\
\hline
\end{tabular}

Berdasarkan tabel total kebutuhan fan static pressure peralatan pengkondisian udara pada lantai 1 diatas, terlihat bahwa kebutuhan fan static pressure terbesar dialami oleh FCU1-6. Hal ini dikarenakan debit udara yang mengalir didalam saluran udara FCU 1-6 cukup besar sedangkan dimensi dari saluran udaranya cukup kecil sehingga menyebabkan pressure drop yang terjadi disepanjang alirancukup besar dan menjadi yang terbesar pada lantai 1 . Sedangkan yang terkecil terjadi pada FCU1-10 dimana pada peralatan pengkondisian udara ini debit udaranya jauh lebih kecil dari yang lain sedangkan dimensiductingnya tergolong besar untuk ukuran debit udara yang mengalir didalamnya sehingga pressure drop yangtimbul disepanjang aliran juga cukup kecil.

Tabel 6.

Total Kebutuhan Fan Static Pressure Peralatan Pengkondisian Udara Pada Lantai 2

\begin{tabular}{|c|c|c|c|c|c|}
\hline $\begin{array}{l}\text { FCU } \\
\text { Lt.2 }\end{array}$ & $\begin{array}{l}\text { Exit } \\
(\mathbf{P a})\end{array}$ & $\begin{array}{c}\text { Saluran } \\
\text { Lurus } \\
\text { (Pa) }\end{array}$ & $\begin{array}{c}\text { Elbow } \\
9^{\circ}(\mathrm{Pa})\end{array}$ & $\begin{array}{r}\text { Diverging } \\
\text { Wye (Pa) }\end{array}$ & $\begin{array}{c}\text { Static Pressure } \\
\text { (Pa) }\end{array}$ \\
\hline FCU 201 & 11.53 & 6.89 & & 6.30 & 24.72 \\
\hline FCU 202 & 1.31 & 0.79 & & 0.96 & 3.06 \\
\hline FCU 203 & 11.53 & 6.87 & & 6.30 & 24.69 \\
\hline FCU 204 & 2.05 & 1.18 & & 1.49 & 4.73 \\
\hline FCU 205 & 0.95 & 0.95 & 2.47 & 0.79 & 5.15 \\
\hline FCU 206 & 0.43 & 0.29 & & 0.37 & 1.08 \\
\hline FCU 207 & 0.31 & 0.48 & 1.05 & & 1.85 \\
\hline FCU 208 & 0.53 & 0.76 & 1.81 & & 3.10 \\
\hline FCU 209 & 7.05 & 5.51 & & 2.80 & 15.36 \\
\hline FCU 210 & 1.31 & 0.80 & & 0.96 & 3.06 \\
\hline FCU 211 & 7.05 & 5.51 & & 2.80 & 15.36 \\
\hline FCU 212 & 1.31 & 0.80 & & 0.96 & 3.06 \\
\hline FCU 214 & 1.31 & 0.80 & & 0.96 & 3.06 \\
\hline FCU 215 & 7.05 & 5.51 & & 2.80 & 15.36 \\
\hline FCU 216 & 0.49 & 0.85 & 1.68 & & 3.03 \\
\hline FCU 217 & 0.47 & 0.68 & 1.24 & & 2.39 \\
\hline FCU 218 & 0.47 & 0.68 & 1.24 & & 2.39 \\
\hline FCU 219 & 0.94 & 1.25 & 2.51 & & 4.70 \\
\hline FCU 220 & 0.68 & 0.88 & 4.94 & & 6.50 \\
\hline FCU 221 & 5.39 & 3.17 & & 3.14 & 11.71 \\
\hline FCU 222 & 2.64 & 1.51 & & 1.97 & 6.12 \\
\hline FCU 223 & 5.39 & 3.17 & & 3.14 & 11.71 \\
\hline FCU 224 & 5.20 & 2.86 & & 3.26 & 11.33 \\
\hline FCU 225 & 2.64 & 3.64 & 8.94 & & 15.21 \\
\hline FCU 226 & 1.15 & 1.77 & 3.90 & & 6.83 \\
\hline FCU 227 & 2.04 & 2.66 & 5.40 & & 10.10 \\
\hline FCU 228 & 2.04 & 2.66 & 5.40 & & 10.10 \\
\hline FCU 229 & 2.04 & 2.66 & 5.40 & & 10.10 \\
\hline FCU 230 & 0.67 & 0.95 & 2.27 & & 3.89 \\
\hline FCU 231 & 3.27 & 2.29 & & 1.28 & 6.84 \\
\hline FCU 232 & 2.62 & 1.51 & & 1.92 & 6.05 \\
\hline FCU 233 & 3.27 & 2.29 & & 1.28 & 6.84 \\
\hline FCU 234 & 2.63 & 1.51 & & 1.93 & 6.07 \\
\hline FCU 235 & 3.27 & 2.29 & & 1.28 & 6.84 \\
\hline FCU 236 & 2.63 & 1.51 & & 1.93 & 6.07 \\
\hline FCU 237 & 1.75 & 2.20 & 12.62 & & 16.56 \\
\hline FCU 238 & 1.06 & 1.40 & 2.80 & & 5.26 \\
\hline FCU 239 & 0.47 & 0.68 & 1.24 & & 2.39 \\
\hline FCU 240 & 0.47 & 0.68 & 1.24 & & 2.39 \\
\hline FCU 241 & 0.91 & 0.85 & 1.68 & & 3.44 \\
\hline
\end{tabular}

Sama halnya pada lantai 1 , pada tabel total kebutuhan fan static pressure pada lantai 2 diatas, juga ditemukan peralatan pengkondisian udara dengan kebutuhan fan static pressure terbesar yang dialami oleh FCU 201. Hal ini juga disebabkan karena debit udara yang mengalir didalam saluran udara FCU 201 cukup besar sedangkan dimensi saluran udaranya cukup kecil menyebabkan pressure drop yang terjadi disepanjang 
aliran cukup besar. Sedangkan yang terkecil terjadi pada FCU 206 dikarenakan debit udara yang mengalir didalam saluran tergolong cukup kecil untuk dimensi saluran udaranya yang tergolong besar.

Ketika kapasitas pendinginan berdasarkan perhitungan ulang ternyata lebih kecil dari desain awal, maka akan menyebabkan temperatur udara didalam ruangan yang dikondisikan lebih rendah dari temperatur yang direncanakan sehingga akan dijumpai kondisi yang kurang nyaman pada ruangan tersebut. Begitu pula ketika kapasitas pendinginan berdasarkan perhitungan ulang lebih besar dari desain awal, maka akan menyebabkan kondisi yang kurang nyaman pada ruangan dikarenakan temperatur ruangan yang dihasilkan lebih besar dari temperatur ruangan yang direncanakan.

Sama halnya dengan kapasitas pendinginan, kelebihan debit udara suplai juga akan menyebabkan kondisi yang kurang nyaman pada ruangan dikarenakan temperatur yang dihasilkan lebih rendah dari temperatur ruangan yang direncanakan. Begitupun sebaliknya, kekurangan debit udara suplai juga akan menyebabkan temperatur ruangan yang dihasilkan lebih besar dari temperatur ruangan yang direncanakan menyebabkan ruangan yang dikondisikan menjadi kurang nyaman. Hal ini dikarenakan perhitungan kebutuhan debit udara didasarkan pada beban pendinginan pada ruangan sehingga ketika debit udara lebih kecil dari hasil perhitungan, maka tidak mampu untuk menanggulangi beban pendinginan yang terjadi pada ruangan, akibatnya temperatur yang dihasilkan nantinya lebih besar dari yang direncanakan pada kondisi nyaman.

Pada lantai 1 terdapat beberapa peralatan pengkondisian udara yang mengalami kekurangan kapasitas pendinginan dan debit udara suplai yang cukup besar sehingga perlu dilakukan penambahan unit peralatan pengkondisian udara agar kapasitas pendinginan serta kapasitas udara suplai dapat disesuaikan dengan kebutuhan kapasitas pendinginan dan udara suplai hasil perencanaan ulang pada kondisi nyaman. Untuk lantai 2, tidak perlu dilakukan penambahan unit pengkondisian udara. Yang perlu dilakukan hanya pengalihan sebagian udara suplai dari peralatan pengkondisian udara yang mengalami kelebihan terhadap peralatan pengkondisian yang justru mengalami kekurangan kapasitas pendinginan serta udara suplai agar nantinya keseluruhan ruangan yang dikondisikan dapat mencapai ruangan dengan kondisi nyaman.

Selain itu, hal yang perlu diperhatikan ialah pengaturan bukaan damper pada saluran udara. Halini bertujuan untuk menjaga agar debit udara yang disuplai nantinya sesuai dengan kebutuhan udara suplai untuk tiap ruangan sekaligus untuk menjaga agar debit udara suplai dapat disalurkan secara merata kedalam ruangan yang dikondisikan. Pengaturan kecepatan putaran kompresor dengan pemasangan inverter pada unit pengkondisian udara juga perlu dilakukan agar debit chilled water dapat menyesuaikan dengan kapasitas pendinginan yang dibutuhkan sehingga penghematan energi dapat tercapai

\section{KESIMPULAN}

Kesimpulan yang didapatkan dari hasil penelitian tugas akhir ini adalah sebagai berikut:

1. Dari perbandingan desain awal terhadap perencanaan ulang diketahui terdapat peralatan pengkondisian udara dengan kapasitas pendinginan dan debit udara suplai lebih besar dari perencanaan ulang. Hal ini menyebabkan kondisi ruangan menjadi kurang nyaman dikarenakan temperatur ruangan akan menjadi lebih kecil dari yang direncanakan. Peralatan pengkondisian udara yang dimaksud ialah FCU 1-4, FCU 1-9, FCU 1-10, FCU 202, FCU 204, FCU 205, FCU 206, FCU 207, FCU 208, FCU 210, FCU 212, FCU 214, FCU 216, FCU 217, FCU 218, FCU 219, FCU 220, FCU 222, FCU 224, FCU 226, FCU 227, FCU 228, FCU 229, FCU 230, FCU 232, FCU 234, FCU 236, FCU 238, FCU 239, FCU 240 dan FCU 241.

2. Dari perbandingan desain awal terhadap perencanaan ulang diketahui terdapat peralatan pengkondisian udara dengan kapasitas pendinginan dan debit udara suplai lebih kecil dari perencanaan ulang. Hal ini menyebabkan kondisi ruangan menjadi kurang nyaman dikarenakan temperatur ruangan akan menjadi lebih besar dari yang direncanakan. Peralatan pengkondisian udara yang dimaksud ialah AHU 1-1, AHU 1-2, FCU 1-1, FCU 1-2, FCU 1-3, FCU 1-6, FCU 1-7, FCU 1-8, FCU 1-11, FCU 201, FCU 203, FCU 209, FCU 211, FCU 215, FCU 221, FCU 223, FCU 225, FCU 231, FCU 233, FCU 235 dan FCU 237.

3. Dari hasil perhitungan perencanaan ulang didapatkan besar kebutuhan fan static pressure tiap peralatan pengkondisian udara untuk mensirkulasikan udara didalam system termasuk menyalurkan udara suplai keruangan yang dikondisikan dimana kebutuhan static pressure fan terbesar ialah pada FCU 1-6 sebesar 318,33 Pa dan yang terkecil pada FCU 206 sebesar 1,08 Pa.

\section{UCAPAN TERIMA KASIH}

Ucapan terima kasih penulis sampaikan kepada bapak Ary Bachtiar K.P., ST, MT, Ph.D selaku pembimbing penelitian tugas akhir ini. Penulis juga mengucapkan terima kasih kepada Jurusan Teknik Mesin FTI-ITS yang telah memberikan dukungan terhadap penelitian tugas akhir ini.

\section{DAFTAR PUSTAKA}

[1] ASHRAE. ASHRAE-HANDBOOK-1997 Fundamental. Atlanta: American Society of Heating, Refrigeration and Air Conditioning Engineers.

[2] R.W. Fox and A.T. McDonald, "SI Version Introducing To Fluid Mechanics Seventh Edition," (2008)

[3] F. P. Incopera, "Fundamental of Heat and Mass Transfer, Seventh Edition," New York: John Willey \& Sons, Inc (2011).

[4] M.J. Moran and H.N. Shapiro, "Fundamental of Engineering Thermodynamics Third Edition," New York: John Willey and Sons, inc (1998).

[5] Edward G. Pita, "Air Conditioning Principles and Systems An Energy Approach,” USA: John Willet \& Sons (1981). 